\title{
Comparison of midforceps, low-forceps, and spontaneous vaginal deliveries
}

\author{
JOSEPH H. TEDESCO, DO
}

A prospective, six-month study compared various maternal and neonatal parameters among spontaneous vaginal $(n=47)$, low-forceps $(n=21)$, and midforceps $(n=15)$ deliveries. All three groups had good neonatal and maternal outcomes. The only significant differences $(P>.01)$ were the one-minute Apgar scores between the low-forceps and midforceps groups and parity between the spontaneous vaginal and low-forceps deliveries. The findings did not reveal poorer neonatal outcomes or excessive maternal morbidity, thus supporting the continued use of forceps in properly selected patients.

Prior to the advent of modern forceps, often one or both lives were lost in labor. However, Peter Chamberlen invented the prototype for presentday forceps in the late $1500 \mathrm{~s}^{1}$ This was a wellkept family secret for more than 100 years, with services being rendered to the nobility and elite. Eventually, the design was discovered and many advances have been made since, resulting in improved maternal and neonatal survival.

The advancement of operative obstetrics and anesthesia has provided the option of cesarean section, which carries low risks of morbidity and mortality. Also, with the present medicolegal dilemma facing the practicing obstetrician, the rising cesarean section rate and declining use of forceps are understandable. However, this trend also is causing new obstetricians and gynecologists to have only limited training and experience with midforceps use and techniques. . $^{2,3}$

The present study was undertaken to evaluate vaginal deliveries performed by the resident staff of a small community hospital. The outcomes of spontaneous vaginal deliveries (SVD), low-forceps deliveries (LFD), and midforceps deliveries (MFD) were compared. The staff's hypothesis was that forceps deliveries, when performed properly and selectively, would yield acceptable maternal and neonatal results, even though this attitude does not pervade the general obstetrics community in which we practice.

\section{Materials and methods}

The study population consisted of women who underwent vaginal deliveries managed by obstetric residents at Phoenix General Hospital between February 1986 and July 1986 . The subjects were patients of the obstetrics clinic of the hospital or came from the private practice of the obstetrics department's chief trainer. All patient data, including antepartum, intrapartum, and postpartum information, were logged prospectively. Virtually all patients were monitored with a Corometrics 115 electronic fetal monitor; whether the monitoring was external or internal depended on the status of membranes. Intrauterine pressure catheters were used only for select patients who had undergone cesarean section previously, or when the external transducer yielded an unsatisfactory tracing.

Apgar scores were assigned by the attending pediatrician, or by the obstetrician when no pediatrician was in attendance. A pediatrician was present for all midforceps and most low-forceps deliveries, and for spontaneous vaginal deliveries when signs of fetal distress or meconium were present. A Corometrics $220 \mathrm{pH}$ monitor was used to monitor the umbilical venous $\mathrm{pH}$ value immediately after the infant was delivered. This datum was made available to the attending pediatrician. The $\mathrm{pH}$ monitor was calibrated monthly, and no changes had to be made with the unit during the study period.

Maternal charts were reviewed for evidence of morbidity secondary to mode of delivery, such as excessive blood loss $(>500 \mathrm{~mL})$, cervical or vaginal lacerations, or extension of episiotomy. 
TABLE 1. MEAN SCORES FOR STUDY POPULATION $(\mathrm{N}=83)$.

\begin{tabular}{lllllll|}
\hline Parameter & SVD & \pm SD & LFD & \pm SD & MFD & \pm SD \\
\hline Maternal age (yr) & 25.2 & 4.24 & 23.2 & 6.15 & 24.7 & 4.97 \\
Gestational age (wk) & 39.1 & 1.68 & 40.2 & 2.06 & 39.9 & 1.73 \\
Umbilical vein pH value & 7.36 & 0.19 & 7.34 & 0.44 & 7.35 & 0.21 \\
One-minute Apgar score & 7.6 & 0.87 & 7.8 & 1.03 & 6.7 & 0.50 \\
Five-minute Apgar score & 8.9 & 0.10 & 8.7 & 0.63 & 8.5 & 0.50 \\
Gravidity & 3.0 & 1.29 & 2.2 & 2.38 & 2.5 & 1.62 \\
Parity & 1.30 & 1.17 & 0.52 & 0.74 & 0.87 & 1.24 \\
Key: SVD = spontaneous vaginal delivery; LFD =low-forceps delivery; and MFD = midforceps delivery.
\end{tabular}

TABLE 2. MATERNAL MORBIDITY.

\begin{tabular}{lccc|}
\hline Complication & SVD & LFD & MFD \\
\hline Third-degree tear & 2 & 1 & 1 \\
Fourth-degree tear & 1 & 0 & 0 \\
Vaginal wall tear & 0 & 1 & 2 \\
Cervical lacerations & 0 & 0 & 0 \\
Blood loss $>500 \mathrm{~mL}$ & 0 & 0 & 0 \\
Fever & 0 & 0 & 1
\end{tabular}

$\overline{\text { Key }: \mathrm{SVD}}=$ spontaneous vaginal delivery; $\mathrm{LFD}=$ low-forceps delivery; and $\mathrm{MFD}=$ mid-forceps delivery.

\begin{tabular}{|c|c|c|c|}
\hline Complication & SVD & LFD & MFD \\
\hline Skull fracture & 0 & 0 & 0 \\
\hline Cephalohematoma & 0 & 0 & 0 \\
\hline Neurologic sequelae & 0 & 0 & 0 \\
\hline Spontaneous & & & \\
\hline pneumothorax & 0 & 1 & 1 \\
\hline $\begin{array}{l}\text { Respiratory distress } \\
\text { syndrome }\end{array}$ & 1 & 0 & 0 \\
\hline
\end{tabular}

Neonatal charts also were scanned for evidence of trauma secondary to forceps use, such as cephalohematoma, skull fracture, or neurologic sequelae.

In our hospital, midforceps delivery is defined as the use of forceps when the fetal head is engaged in the pelvis but no scalp is showing on the perineum, or when rotation is performed on the fetal head. ${ }^{1}$ Midforceps procedure was selected when the second stage of labor became prolonged, persistent occipital transverse or posterior positioning occurred, midplane arrest occurred, or fetal distress intervened, and when the fetal head met the requirements for midforceps use. Epidural anesthesia was used for all midforceps deliveries; in some instances, anesthesia had already been achieved, and in some instances, induction of anesthesia had been started when the decision to use forceps was made.
Low-forceps delivery is defined as the application of forceps when the fetal scalp is visible on the perineum without spreading the labia. ${ }^{1}$ Lowforceps procedure was used when there was a prolonged second stage of labor or when fetal distress occurred. The type of anesthesia varied, with a range from local perineal to continuous epidural anesthesia.

Spontaneous vaginal deliveries were followed similarly, with anesthesia ranging from none to epidural block, depending on the patient's desires.

The data obtained were logged, then compared using the Student's $t$-test for seven factors to ascertain whether the groups were matched evenly and whether any statistical differences occurred between groups. A $P$ value of .01 was selected at the beginning of the study, because it was thought that differences beyond this would be truly significant.

\section{Results}

The mean values for the seven initial parameters for the study group of 83 women are listed in Table 1.

Maternal and neonatal complications for the three groups are presented in Tables 2 and 3, respectively. The incidence of problems encountered with the use of forceps was minimal. Only three neonates required intensive care, two because of spontaneous pneumothoraces, which resolved without chest tube placement, and one with respiratory distress syndrome, who was born at 30 weeks' gestation via spontaneous vaginal delivery. No fetal morbidity could be associated with the use of forceps in our study group. Shoulder dystocia was not a complicating factor in our study; only two mild cases were encountered, one in the SVD and one in the MFD group, and both were reduced easily. Maternal complications were thought to be acceptable; no hemorrhage occurred, and there was only one instance of maternal fever, which was associated with acute chorioamnionitis.

By reviewing Tables 4, 5, and 6, one can see that the groups were matched fairly evenly, and that 


\begin{tabular}{|c|c|c|c|}
\hline Parameter & $\operatorname{SVD}(n=47)$ & $\operatorname{LFD}(n=21)$ & $P$ value \\
\hline Maternal age (yr) & 25.2 & 23.2 & NS \\
\hline Gestational age (wk) & 39.1 & 40.2 & NS \\
\hline $\begin{array}{l}\text { Umbilical vein } \mathrm{pH} \\
\text { value }\end{array}$ & 7.36 & 7.34 & NS \\
\hline $\begin{array}{l}\text { One-minute Apgar } \\
\text { score }\end{array}$ & 7.6 & 7.8 & NS \\
\hline $\begin{array}{l}\text { Five-minute Apgar } \\
\text { score }\end{array}$ & 8.9 & 8.7 & NS \\
\hline Gravidity & 3.0 & 2.2 & NS \\
\hline Parity & 1.30 & 0.52 & $>.01$ \\
\hline
\end{tabular}

the outcomes were similar when comparing umbilical vein $\mathrm{pH}$ values and Apgar scores. The only statistical differences noted were for parity between the SVD and LFD groups and the one-minute Apgar scores between the LFD and MFD groups.

Table 7 lists our reasons for midforceps use in the study group. There was some overlapping because of the association of fetal distress with other midplane problems.

During the study period, there was only one unsuccessful midforceps rotation delivery. The forceps could not be properly applied, and the attempt was abandoned. A viable neonate was delivered by cesarean section. The Apgar scores were good and there were no forceps marks. On vaginal examination, no maternal cervical or vaginal tears were noted.

\section{Discussion}

The medical advances made in recent years have allowed for closer scrutiny of the maternal-fetal environment, and this, in turn, has led to improved obstetric care. Also, however, the medical field has come under closer surveillance by the legal profession. This has caused many practicing obstetricians to opt for cesarean section when there is any possibility of a less-than-optimal outcome, because of the feeling that this decision is more defensible.

However, recent studies have shown that when forceps deliveries are compared closely with cesarean sections, there are no obvious advantages to performing a cesarean. Dierker and associates ${ }^{2}$ found no increases in neonatal morbidity. A review by Richardson and coworkers ${ }^{4}$ clearly projected the efficacy of forceps delivery in yielding acceptable maternal and neonatal outcomes. They were also able to point out flaws in a previous study by Friedman and associates ${ }^{5,6}$ that suggested poorer out-

\begin{tabular}{|c|c|c|c|}
\hline Parameter & $\operatorname{SVD}(n=47)$ & $\operatorname{MFD}(n=15)$ & $P$ value \\
\hline Maternal age (yr) & 25.2 & 24.7 & NS \\
\hline Gestational age (wk) & 39.1 & 39.9 & NS \\
\hline $\begin{array}{l}\text { Umbilical vein } \mathrm{pH} \\
\text { value }\end{array}$ & 7.34 & 7.35 & NS \\
\hline $\begin{array}{l}\text { One-minute Apgar } \\
\text { score }\end{array}$ & 7.6 & 6.7 & NS \\
\hline $\begin{array}{l}\text { Five-minute Apgar } \\
\text { score }\end{array}$ & 8.9 & 8.5 & NS \\
\hline Gravidity & 3.0 & 2.5 & NS \\
\hline Parity & 1.30 & 0.87 & NS \\
\hline
\end{tabular}

\begin{tabular}{|c|c|c|c|}
\hline Parameter & $\operatorname{LFD}(n=21)$ & $\operatorname{MFD}(n=15)$ & $P$ value \\
\hline Maternal age (yr) & 23.2 & 24.7 & NS \\
\hline Gestational age (wk) & 40.2 & 39.9 & NS \\
\hline Umbilical vein $\mathrm{pH}$ value & 7.34 & 7.35 & NS \\
\hline $\begin{array}{l}\text { One-minute Apgar } \\
\text { score }\end{array}$ & 7.8 & 6.7 & $>.01$ \\
\hline $\begin{array}{l}\text { Five-minute Apgar } \\
\text { score }\end{array}$ & 8.7 & 8.5 & NS \\
\hline Gravidity & 2.2 & 2.5 & NS \\
\hline Parity & 0.52 & 0.87 & NS \\
\hline
\end{tabular}

\begin{tabular}{|l|}
\hline TABLE 7. REASONS FOR MIDFORCEPS USE. \\
\hline Reason
\end{tabular}

come among neonates delivered by the midforceps procedure.

There is evidence that forceps use continues to decline and that this trend will self-perpetuate, with new residents being less than optimally trained in midforceps techniques. ${ }^{2}$ Laube $^{3}$ stated that the rate of midforceps use in a major teaching 
hospital was only $2 \%$, with roughly one half of those involving rotation.

In our hospital, forceps still are used when applicable, and training of forceps skills continues. During the six months of our study, the use rate of various delivery modes was as follows: SVD, $62 \%$; LFD, $12 \%$; MFD, $7 \%$; primary cesarean section, $14 \%$; and repeat cesarean section, $5 \%$. We think that these rates compare favorably with national statistics, and, it is hoped, we can continue to provide good obstetric care without succumbing to the legal issues now ensnaring our field.

As our study demonstrates, forceps use yielded excellent results in terms of maternal and neonatal outcomes when compared with routine vaginal deliveries, which is a difficult comparison to make considering the myriad variables involved in labor and delivery.

Previous studies have shown that Apgar scoring is useful only in terms of initial resuscitation needs of the neonate, yet these numbers often are given undue credence when rating the obstetrician's management decisions. Our values were comparable between groups, with the only statistical difference noted in the one-minute score between LFD and MFD.

It has been shown that even with Apgar scores of 3 or less at five minutes, more than $96 \%$ of the children had no mental retardation. ${ }^{7}$ Sykes and associates, ${ }^{8}$ in a prospective study of more than 1,200 deliveries, showed that Apgar scores usually do not reflect the degree of acidosis at delivery. Therefore, the Apgar score must be questioned as an index for asphyxial assessment. ${ }^{7-10}$

More recently, umbilical cord $\mathrm{pH}$ values have been used to determine whether intrauterine asphyxia with acidosis has occurred. This may be shown to be a more useful determination, yet wide variations also have been noted for these values. ${ }^{11}$ Our study yielded quite similar results consistently, which suggests that proper forceps use does little to affect the fetus detrimentally.

It is my opinion that forceps continue to hold a valuable place in obstetrics when used judiciously.

\section{Conclusions}

As modern obstetricians continue to provide better health care for mothers and infants, one must continually try to improve on the care given. The history of obstetrical forceps and their rise and fall in favor may lead one to think they are no longer of benefit. I feel that the data provided here shows that they have a place in the modern obstetrical practice. This may become even more evident in the near future as the cry now is to lower cesarean section rates.
We must, however, as members of the profession, always meet the high standards set before us and not let outside influences force us into providing less-than-optimal care.

1. Danforth DN: Obstetrics and Gynecology, ed 4. Harper \& Row Publishers, Inc, New York 1982, pp 7-9, 695-706.

2. Dierker LJ Jr, Rosen MG, Thompson K, et al: The midforceps: Maternal and neonatal outcomes. Am J Obstet Gynecol 1985;152:176-183.

3. Laube DW: Forceps delivery. Clin Obstet Gynecol 1986;29:286-298.

4. Richardson DA, Evans MI, Cibils LA, et al: Midforceps delivery: A critical review. Am J Obstet Gynecol 1983;145:621-632.

5. Friedman EA, Sachtleban MR: High risk labor. $J$ Reprod Med 1971;7:28-32.

6. Friedman EA, Sachtleban MR, Bresky PA: Dysfunctional labor. XII. Long-term effects on infant. Am J Obstet Gynecol 1977;127:779-783.

7. Paneth N, Fox HE: The relationship of Apgar score to neurologic handicap: A survey of clinicians. Obstet Gynecol 1983;61:547-550.

8. Sykes GS, Molloy PM, Johnson P, et al: Do Apgar scores indicate asphyxia? Lancet 1982;1:494-496.

9. Goldenberg RL, Huddleston JF, Nelson KG: Apgar scores and umbilical arterial $\mathrm{pH}$ in preterm newborn infants. Am $J$ Obstet Gynecol 1984;149:651-654.

10. Modanlou H, Yeh SY, Hon EH, et al: Fetal and neonatal biochemistry and Apgar scores. Am J Obstet Gynecol 1973;117:942-951.

11. Yeomans ER, Hauth JC, Gilstrap LC III, et al: Umbilical cord pH, $\mathrm{PCO}^{2}$, and bicarbonate following uncomplicated term vaginal deliveries Am J Obstet Gynecol 1985;151:798-800.

From the Department Of Obstetrics and Gynecology, Phoenix General Hospital, Phoenix.

Reprint requests to Dr Tedesco, 4633 N 21st Ave, Phoenix 85015 . 


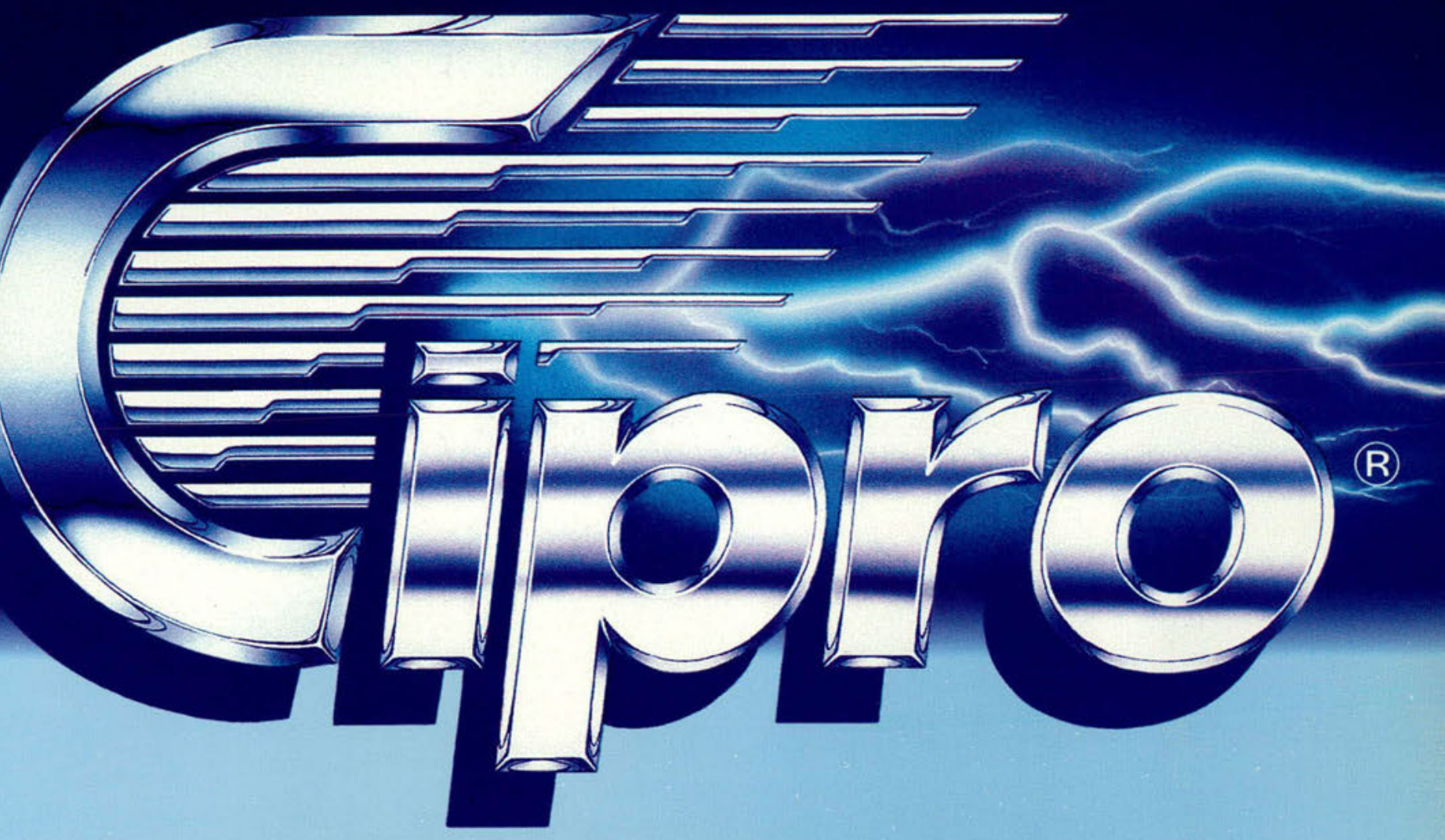

(ciprofloxacin HCl/Miles)

A REVOLUTIONARY

ORAL ANTIMICROBAL 


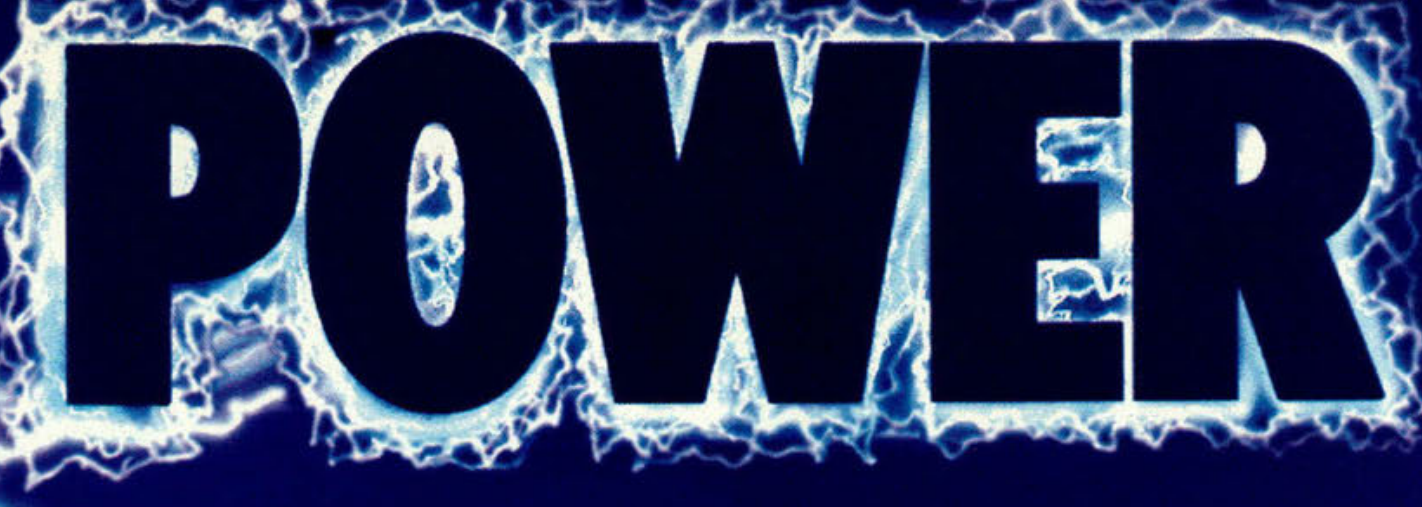

\section{OFPARENTERALS}

- Highly active in vitro against a broad range of gram-positive and gram-negative pathogens, including Pseudomonas aeruginosa and methicillin-resistant Staphylococcus aureus"

For treatment of infections in the:
- lower respiratory tract - urinary tract
- skin/skin structure - bones and joints

\section{Well tolerated - low incidence of side effects}

For further information, contact the Miles Information Service:

1-800-642-4776. (In VA, call collect: 703-391-7888.)

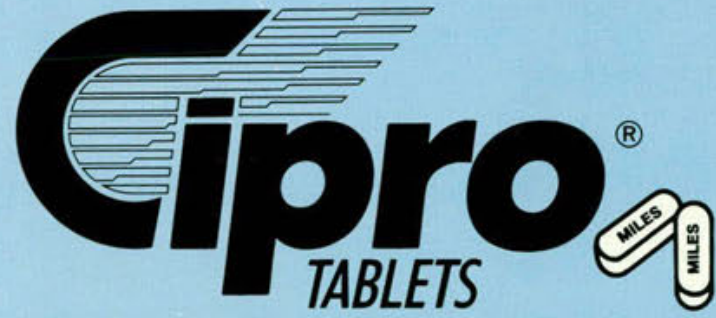

THE POWER OF PARENTERALS THE FREEDOM OF ORAL DOSAGE 


\section{Gipro (ciprofloxacin $\mathrm{HCl} /$ Miles) \\ CONVENIENT B.I.D. DOSAGE Dosage guidelines Mild/Moderate Infections*: $500 \mathrm{mg}$ q12h Severe/Complicated Infections*: $750 \mathrm{mg}$ q12h}

\author{
CIPRO' TABLETS \\ (ciprofloxacin $\mathrm{HCl} / \mathrm{Miles}$ ) \\ BRIEF SUMMARY
}

CONSULT PACKAGE INSERT FOR FULL PRESCRIBING INFORMATION

INDICATIONS AND USAGE

Cipro" is indicated for the treatment of infections caused by susceptible strains of the designated microorganisms in

Lower Respiratory Intections caused by Escherichia coll, Klebsiella pneumoniae, Enterobacter cloacae, Proteus mirabills, Pseudomonas aeruginosa, Haemophilus influenzae, Haemophilus parainfluenzae, and Streptococcus pneumoniae.

Skin and Skin Structure Infections caused by Escherichia coll, Klebsiella pneumoniae, Enterobacter cloacae, Proteus mirabilis, Proteus vulgaris, Providencia stuartï, Morganella morganii, Citrobacter freundii, Pseudomonas aeruginosa, Staphylococcus aureus, Staphylococcus epidermidis, and Streptococcus pyogenes.

Bone and Joint Infections caused by Enterobacter cloacae, Serratia marcescens, and Pseudomonas aeruginosa Urinary Tract Infections caused by Escherichia coli, Klebsiella pneumoniae, Enterobacter cloacae, Serratia marcescens, Proteus mirabilis, Providencia rettoeri. Morganella morganii, Citrobacter diversus, Citrobacter freundivi, Pseudomonas aeruginosa, Staphylococcus epidermidis, and Streptococcus faecalis.

Infectious Diarrhea caused by Escherichia coll' (enterotoxigenic strains), Campylobacter jejuni, Shigella flexneri. . and Shigella sonnei ${ }^{*}$ when antibacterial therapy is indicated

"Efficacy for this organism in this organ system was studied in fewer than 10 infections.

CONTRAINDICATIONS

A history of hypersensitivity to ciprofloxacin is a contraindication to its use. A history of hypersensitivity to other quinolones may also contraindicate the use of ciprofloxacin.

CIPROFLJXACIN SHÓULD NOT BE USED IN CHILDREN, ADOLESCENTS, OR PREGNANT WOMEN. The oral administration of ciprofloxacin caused lameness in immature dogs. Histopathological examination of the weight-bearing
joints of these dogs revealed permanent lesions of the cartilage. Related drugs such as nalidixic acid, cinoxacin, and norfloxacin also produced erosions of cartilage of weight-bearing joints and other signs of arthropathy in immature animals of various species (SEE ANIMAL PHARMACOLOGY SECTION IN FULL PRESCRIBING INFORMATION). PRECAUTIONS

General: As with other quinolones, ciprofloxacin may cause central nervous system (CNS) stimulation, which may lead to tremor, restlessness, lightheadedness, confusion, and rarely to hallucinations or convulsive seizures. Therefore, ciprofloxacin should be used with caution in patients with known or suspected CNS disorders, such as severe cerebral arteriosclerosis or epilepsy, or other factors which predispose to seizures (SEE ADVERSE REACTIONS). Anaphylactic reactions following the first dose have been reported in patients receiving therapy with quinolones. Some reactions were accompanied by cardiovascular collapse, loss of consciousness, tingling, pharyngeal or facial edema, dyspnea, urticaria, and itching. Only a few patients had a history of hypersensitivity reaction. Anaphylactic reactions may require epinephrine

Signere hypersensitivity reactions characterized by rash, fever, eosinophilia, jaundice, and hepatic necrosis with Severe hypersensitvity reactions characterized by rash, fever, eosinophilia, jaundice, and hepatic necrosis with
tatal outcome have been reported rarely (less than one per million prescriptions) in patients receiving ciprofloxacin latal outcome have been reported rarely (less than one per million prescriptions) in patients receiving ciprofloxacin
along with other drugs. The possibility that these reactions were related to ciprofloxacin cannot be excluded. along with other drugs. The possibility that these reactions were related to ciprofloxacin cannot be excluded.
Ciprofloxacin should be discontinued at the first appearance of a skin rash or any sign of other hypersensitivity reaction.

Crystals of ciprofloxacin have been observed rarely in the urine of human subjects but more frequently in the urine of laboratory animals (SEE ANIMAL PHARMACOLOGY SECTION IN FULL PRESCRIBING INFORMATION). Crystalluria of laboratory animals (SEE ANIMAL PHARMACOLOGY SECTION IN FULL PRESCRIBING INFORMATION). Crystalluria
related to ciprofloxacin has been reported only rarely in man, because human urine is usually acidic. Patients receiving ciprofloxacin should be well hydrated, and alkalinity of the urine should be avoided. The recommended daily dose should not be exceeded. Alteration of the dosage regimen is necessary for patients with impairment of renal dose should not be exceeded. Alteration of the cose
function (SEE DOSAGE AND ADMINISTRATION).

As with any potent drug, periodic assessment of organ system functions, including renal, hepatic, and hematoAs with any potent drug, periodic assessment of org
poietic function, is advisable during prolonged therapy.

Drug Interactions: As with other quinolones, concurrent administration of ciprofloxacin with theophylline may lead to Orug interactions: As with other quinolones, concurrent administration of ciprofloxacin with theophylline may lead to
elevated plasma concentrations of theophylline and prolongation of its elimination half-life. This may result in elevated plasma concentrations of theophylline and prolongation of its elimination halif-life. This may result in
increased risk of theophylline-related adverse reactions. If concomitant use cannot be avoided, plasma levels of theophylline should be monitored and dosage adiustments made as approprite.

Quinolones, including ciprofloxacin, have also been shown to interfere with the metabolism of caffeine. This may lead to reduced clearance of caffeine and a prolongation of its plasma half-life.

Antacids containing magnesium hydroxide or aluminum hydroxide may interfere with the absorption of ciprofloxacin resulting in serum and urine levels lower than desired; concurrent administration of these agents with ciprofloxacin should be avoided.

Concomitant administration of the nonsteroidal anti-inflammatory drug fenbuten with a quinolone has been reported to increase the risk of CNS stimulation and convulsive seizures.

Probenecid interferes with the renal tubular secretion of ciprofloxacin and produces an increase in the level of ciprofloxacin in the serum. This should be considered if patients are receiving both drugs concomitantly.

As with iner the sern. This should be consideredir patients are recellng both drugs concomitantly. ble organisms. Repeated evaluation of the patient's condition and microbial susceptiblity testing is essential. If superinfection occurs during therapy, appropriate measures should be taken.

Information for Patients: Patients should be advised that ciprofloxacin may be taken with or without meals. The
Inting preferred tim forlints. Patients should be advised that ciprolloxacin may be taken with or without meals. The preterred time of dosing is wo hours atter a meal. Patients should also be advised to drink fluids liberally and not take hypersensitivity rections iven followinum. Patients should be advised that ciprofloxacin may be associated with her allergic reaction. Ciprofloxacin ma a they alloct this dru before they operate an autemobil ightheadedness; therefore patients should know how alertness or coordination. Patients should be advised that ciprofloxacin may increase the effects of theophylline and
caffeine.

Carcinogenesis, Mutagenesis, Impairment of Fertility: Eight in vitro mutagenicity tests have been conducted with ciprofloxacin and the test results are listed below:

Saimonella/Microsome Test (Negative)

E. coll DNA Repair Assay (Negative)

Chise

Chisese

Syrian Hamster Embryo Cell Transformation Assay (Negative)

Saccharomyces cerovisiae Point Mutation Assay (Negative)

Saccharomyces cerevisiae Mitotic Crossover and Gene Conversion Assay (Negative)

Rat Hepatocyte DNA Repair Assay (Positive)

Thus, two of the eight tests were positive, but the results of the following three in vivo test systems gave negative

Rat Hepatocyte DNA Repair Assay

Micronucleus Test (Mice)

ong-term carcinogenicity studies in rats and mice have been completed. After daily oral dosing for up to 2 years, there is no evidence that ciprofloxacin had any carcinogenic or tumorigenic effects in these species.
Pregnancy - Pregnancy Category C: Reproduction studies have been performed in rats and mice at doses up to imes the usual daily human dose and have revealed no evidence of impaired fertility or harm to the fetus due ciprofloxacin. In rabbits, as with most antimicrobial agents, ciprofloxacin ( 30 and $100 \mathrm{mg} / \mathrm{kg}$ orally) produc penicity was observed at either dese. After intravenous administration at doses up to $20 \mathrm{mo} / \mathrm{kg}$. enicly was obsed a was produced, and no embryotoxicity or teratogenicity was observed. There are, however, no adequate and we controlled studies in pregnant women. SINCE CIPROFLOXACIN, LIKE OTHER ORUGS IN ITS CLASS, CAUSE . Nursing Mothers: It is not known whether ciprofloxacin is excreted in human milk, however, it is known th

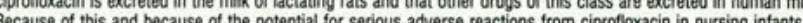

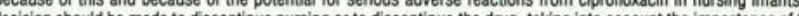
decision should be made to disc drug to the mother.

Pediatric Uso. Patients under the age of 18 were not included in the clinical trials of ciprofloxacin because ciproflo cin as well as other quinolones causes arthropathy in immature animals. Ciprofloxacin should not be used children or adolescents (SEE WARNINGS).

\section{ADVERSE REACTIONS}

Ciprofloxacin is generally well tolerated. During clinical investigation, 2,799 patients received 2,868 courses of drug. Adverse events that were considered likely to be drug related occurred in $7.3 \%$ of courses, possibly related $9.2 \%$, and remotely related in $3.0 \%$. Ciprofloxacin was discontinued because of an adverse event in $3.5 \%$ of course primarily involving the gastrointestinal system (1.5\%), skin $(0.6 \%)$, and central nervous system $(0.4 \%)$. The events typicar of quinolones are italicized.

The most frequently reported events, drug related or not, were nausea (5.2\%), diarrhea (2.3\%), vomiting (2.0\% abdominal pain/discomfort $(1.7 \%)$, headache $(1.2 \%)$, restlessness (1.1\%), and rash $(1.1 \%)$.

GASTROINTESTINAL: (See above), painful oral mucosa, oral candidiasis, dysphagia, intestinal perforatio gastrointestinal bleeding

CENTRAL NERVOUS SYSTEM: (See above), dizziness, lightheadedness, insomnia, nightmares, hallucination manic reaction, irritability, tremor, ataxia, convulsive seizures, lethargy, drowsiness, weakness, malaise, an rexia, phobia, depersonalization, depression, paresthesia.

SKIN/HYPERSENSITVITY. (See above), pruritus, Urticaria, photosensittvity, fiushing, fever, chills, angioedem edema of the face, neck, lips, conjunctivae or hands, cutaneous candidiasis, hyperpigmentation, eryther nodosum.

Allergic reactions ranging from urticaria to anaphylactic reactions have been reported (SEE PRECAUTIONS) SPECIAL SENSES: blurred vision, disturbed vision (change in color perception, overbrightness of light decreased visual acuity, diplopia, eye pain, tinnitus, hearing loss, bad taste.

MUSCULOSKELETAL: joint or back pain, joint stiffness, achiness, neck or chest pain, flare-up of gout.

RENAL/UROGENITAL: interstitial nephritis, nephritis, renal failure, polyuria, urinary retention, urethral bleedin vaginitis, acidosis.

CARDIOVASCULAR: palpitations, atrial flutter, ventricular ectopy, syncope, hypertension, angina pector myocardial infarction, cardiopulmonary arrest, cerebral thrombosis

RESPIRATORY: epistaxis, laryngeal or pulmonary edema, hiccough, hemoptysis, dyspnea, bronchospas pulmonary embolism.

Most of the adverse events reported were described as only mild or moderate in severity, abated soon after drug was discontinued, and required no treatment.

In several instances, nausea, vomiting, tremor, restlessness, agitation, or palpitations were judged by investig tors to be related to elevated plasma levels of theophylline possibly as a result of a drug interaction with ciprofloxaci Other adverse events reported in the postmarketing phase include anaphylactoid reactions, Stevens-Johns syndrome, exfoliative dermatitis, toxic epidermal necrolysis, hepatic necrosis, postural hypotension, possible ex. cerbation of myasthenia gravis, confusion, dysphasia, nystagmus, pseudomembranous colitis, dyspepsia, flat. lence, and constipation. Also reported were agranulocytosis; elevation of serum triglycerides, serum cholesterc blood glucose, serum potassium; prolongation of prothrombin time; albuminuria; candiduria, vaginal candidiasi and renal calcull (SEE PRECAUTIONS).

Adverse Laboratory Changes: Changes in laboratory parameters listed as adverse events without regard to dr relationship:

Hepatic-Elevations of: ALT (SGPT) (1.9\%), AST (SGOT) (1.7\%), alkaline phosphatase $(0.8 \%)$, LDH $(0.4 \%$ serum bilirubin $(0.3 \%)$.

Cholestatic jaundice has been reported.

Hematologic-eosinophilia $(0.6 \%)$, leukopenia $(0.49 \%)$, decreased blood platelets $(0.1 \%)$, elevated bloc platelets ( $0.1 \%)$, pancytopenia $(0.1 \%)$.

Renal-Elevations of: Serum creatinine (1.19\%), BUN $(0.9 \%)$

CRYSTALLURIA, CYLINDRURIA, AND HEMATURIA HAVE BEEN REPORTED.

Other changes occurring in less than $0.1 \%$ of courses were: Elevation of serum gammaglutamyl transferas elevation of serum amylase, reduction in blood glucose, elevated uric acid, decrease in hemoglobin, anemi bleeding diathesis, increase in blood monocytes, and leukocytosis.
OVERDOSAGE

Information on overdosage in humans is not available. In the event of acute overdosage, the stomach should emptied by inducing vomiting or by gastric lavage. The patient should be carefully observed and given supportin treatment. Adequate hydration must be maintained. Only a small amount of ciprofloxacin $(<10 \%)$ is removed fro the body after hemodialysis or peritoneal dialysis. DOSAGE AND ADMINISTRATION

The usual adult dosage for patients with urinary tract infections is $250 \mathrm{mg}$ every 12 hours. For patients wit complicated infections caused by organisms not highly susceptible, $500 \mathrm{mg}$ may be administered every 12 hours Lower respiratory tract infections, skin and skin structure infections, and bone and joint infections may be treat with $500 \mathrm{mg}$ every 12 hours. For more severe or complicated infections, a dosage of $750 \mathrm{mg}$ may be given every hours.

The recommended dosage for infectious diarmea is $500 \mathrm{mg}$ every 12 hours.

In patients with renal impairment, some modification of dosage is recommended (SEE DOSAGE AND ADMINI TRATION SECTION IN FULL PRESCRIBING INFORMATION HOW SUPPLIED

Cipro" (ciprofloxacin HCVMiles) is available as tablets of $250 \mathrm{mg}, 500 \mathrm{mg}$, and $750 \mathrm{mg}$ in bottles of 50 , and in Un Dose packages of 100 (SEE FULL PRESCRIBING INFORMATION FOR COMPLETE DESCRIPTION)

"Due to susceptible strains of indleated pathogens. See Indicated organisms in Prescribing Information.

For further information, contact the Miles Information Service:

1-800-642-4776. In VA, coll collect: 703-391-7888.

COMMITTED TO THERAPEUTIC EFFICIENC)

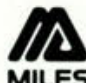

Miles Inc.

Pharmaceutical Divisior 400 Morgan Lane

West Haven, CT 06516

C April 1989, Miles Inc. Printed in U.S.A. C09618 MLR.38 

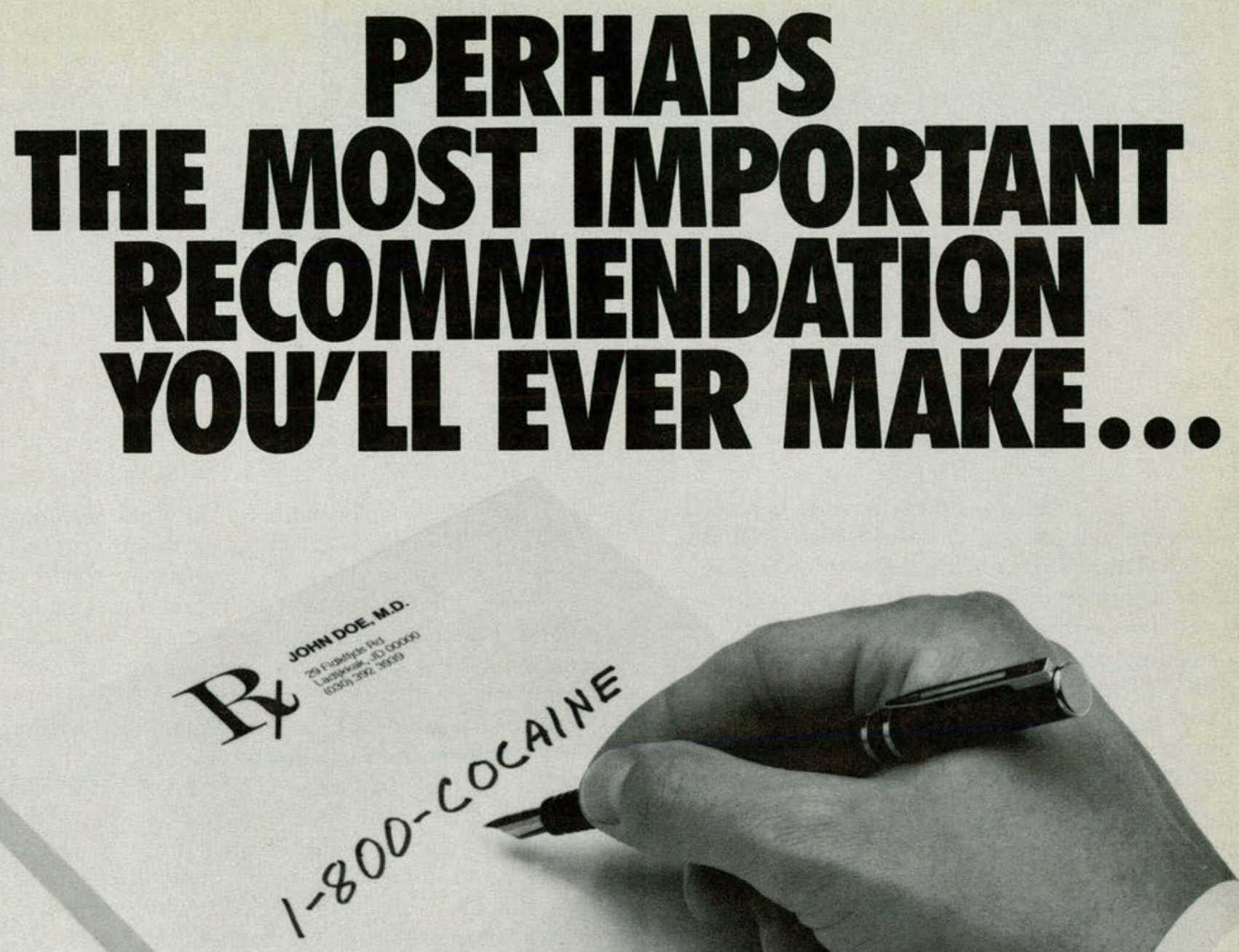

"Cocainism"... a new and tragic American epidemic And your patients are at risk.

Last year, 15 million Americans used cocaine-and 5

million of those who survived required medical help.

You can help abusers end their addiction. Ask them about illegal drug use. Show your concern. Offer your support if they want to stop. And give the National Cocaine Hotline number: 1-800-COCAINE to anyone who seeks your help. It may be the most important recommendation you'll ever make.

\section{MELP STOP SUBSTANCE ABUSE. ASK THE QUESTIONS.}

Partnership for a Drug-Free America 